\title{
Usage of specialized fence-gaps in a black rhinoceros conservancy in Kenya
}

\author{
Marc Dupuis-Désormeaux ${ }^{1}$, Zeke Davidson², Mary Mwololo, \\ Edwin $\mathrm{Kisio}^{3}$ \& Suzanne E. MacDonald ${ }^{4 *}$ \\ 'Department of Biology, York University, Toronto, Ontario, Canada \\ ${ }^{2}$ Marwell Wildlife, Winchester, U.K. \\ ${ }^{3}$ Lewa Wildlife Conservancy, Isiolo, Kenya \\ ${ }^{4}$ Department of Psychology, York University, Toronto, Ontario, Canada \\ Received 18 June 2015. To authors for revision 7 August 2015. Accepted 2 December 2015
}

\begin{abstract}
Fencing is increasingly used in wildlife conservation. Keeping wildlife segregated from local communities, while permitting wildlife access to the greater landscape matrix is a complex task. We investigated the effectiveness of specially designed fence-gaps on animal movement at a Kenyan rhinoceros conservancy, using camera-traps over a four-year period. The fence-gap design restricted the movement of black (Diceris bicornis) and white rhinoceroses (Ceratotherium simum simum) but permitted the movement of other species. We documented over $\mathbf{6 0 0 0}$ crossing events of over $\mathbf{5 0} 000$ individuals which used the fence-gaps to enter or leave the conservancy. We recorded 37 mammal species and two species of bird using the fence-gaps. We conclude that this fence-gap design is effective at restricting rhinoceros movement and at permitting other wildlife movement into and out of the conservancy. We recommend that fenced-in rhinoceros conservancies that desire enhanced connectivity consider this fence-gap design to help re-connect their reserves to the outside landscape matrix while continuing to provide enhanced protection for their rhinoceroses.
\end{abstract}

Key words: fencing, rhino, elephant, connectivity, movement, camera traps, management, corridor.

\section{INTRODUCTION}

Managers entrusted with the protection of wildlife face conflicting demands. On the one hand, managers must protect wildlife and on the other hand, they strive to keep the landscape under their management as close to possible to a natural state, with well-functioning migration and predator-prey dynamics. Habitat fragmentation and connectivity concerns continue to drive conservation discussions (Beier \& Noss, 1998; Debinski \& Holt, 2000; Fahrig, 2007; Newmark, 2008; Packer et al., 2013; Tischendorf \& Fahrig, 2000). Wildlife managers view fences as a useful tool to protect people and wildlife (Hayward \& Kerley, 2009; Hoare, 1992), especially in mixed-use landscapes where communities, roads, and wildlife have to coexist (Newmark, 2008). Keeping wildlife segregated from communities protects wildlife by reducing the likelihood of habitat loss and poaching, and protects people and their livestock from road collisions (McCollister \& Van Manen, 2010), depredation (Hazzah et al., 2014), crop raiding (Kikoti, Griffin \& Pamphii, 2010), and disease (Taylor \& Martin, 1987).

*To whom correspondence should be addressed.

E-mail: suzmac@yorku.ca
Fencing also has many drawbacks, ranging from direct mortality, such as when animals entangle themselves while attempting to leave the fenced habitat, (Albertson, 1998; Harrington \& Conover, 2006; Mbaiwa \& Mbaiwa, 2006) to more subtle ecological changes that can affect long-term population viability by isolation (Atwood et al., 2011), reduced access to resources (Brenneman, Bagine, Brown, Ndetei \& Louis, 2009; Loarie, Aarde \& Pimm, 2009; Olsson \& Widen, 2008), and the creation of edge effects (Massey, King \& Foufopoulos, 2014; Newmark, 2008; Vanak, Thaker \& Slotow, 2010).

Fences are used in road ecology projects in North America and Europe to restrict access to highways and to direct movement to crossing structures (ecopassages) that are designed to permit connectivity (Aresco, 2005; Clevenger, Chruszcz \& Gunson, 2001; Olsson \& Widen, 2008). The fences are meant to guide the animals towards gaps in the fences that permit access to these crossing structures (underpasses or overpasses). Typically, in road ecology projects, the fences are installed at roadkill 'hot spots', as it would be too expensive to fence the whole road. In contrast, in the African wildlife management con- 
text, typically the entire conservancy is fenced. In ecosystems with elephants (Loxodonta africana), fencing can be expensive to maintain (Kioko, Muruthi, Omondi \& Chiyo, 2008) as elephants often break their way through fences (Kioko et al., 2008; Mutinda et al., 2014; Thouless \& Sakwa, 1995) either for migratory purposes or to raid crops. Crop raiding by elephants is a complex problem that requires measured responses (Davies et al., 2011; Guerbois, Chapanda \& Fritz, 2012; R. Hoare, 2012) but migrating elephants tend to use regular travel corridors to link seasonal home ranges (Douglas-Hamilton, Krink \& Vollrath, 2005; Thomas, Holland \& Minot, 2008). These corridors can be accommodated by opening gaps in the fences that, in theory, can allow elephants, and other migratory species, to move in and out of protected areas. Strategically placed fence-gaps, away from agricultural communities and along historical travel routes, could therefore be a useful tool in ongoing efforts to increase connectivity by keeping natural travel corridors open (Beier \& Noss, 1998; Bouché et al., 2011; Di Minin et al., 2013).

Although leaving gaps in fences might be a practical solution to the needs of migrating elephant, for wildlife conservancies hosting endangered black rhinoceros (hereafter black rhino, Diceros bicornis), management must resort to extreme protection measures from poachers by erecting electrical fencing, deploying active surveillance (Walpole \& Leader-Williams, 2002), conducting armed patrols, and implementing shoot-on-sight policies (Messer, 2010). The demands of rhino protection often trump the need for ecological connectivity and for example, more than half of the rhino population in Kenya live in fenced-in conservancies (Kenya Wildlife, 2012). At our study site, management has struck a compromise between rhino protection and elephant migratory needs by designing a fence-gap which allows all large mammal species, except rhino, to migrate in and out of the conservancy. These fence-gaps have been located at sites of historical damage caused by migratory elephants.

The purpose of our study was to test the effectiveness of this special fence-gap design at restricting the movement of rhinos but permitting the movement of other species in an otherwise fenced conservancy in Kenya. We analyzed which species used the fence-gaps and detailed some of the differences in the usage patterns between the fence-gaps, by highlighting differences in traffic volume and species composition. We also wanted to better understand why certain species did not use the fence-gaps and so computed usage ratios based on the traffic volume and the size of the population in situ. Should this fence-gap design prove to be suitable, it may become a cost-effective and useful tool for managers of fenced-conservancies that seek to enhance the connectivity of their protected area.

\section{METHODS}

\section{Study site}

We conducted our study at the Lewa Wildlife Conservancy (Lewa) in Isiolo, Kenya $\left(0.20^{\circ} \mathrm{N}\right.$, $\left.37.42^{\circ} \mathrm{E}\right)$. The habitat consisted of northern Acacia-Commiphora Bushlands and Thickets with an Afromontane section (White, 1983). Lewa was initially a cattle (Bos taurus indicus) ranch (1920-1983) and had a perimeter fence to contain its cattle. In 1983, in response to declining black rhino population, management converted 2000 ha to a rhino sanctuary. This sanctuary grew over the subsequent years and in 1995, Lewa officially converted all of its 25000 ha and upgraded its perimeter fence to a $142 \mathrm{~km}$ long, two-metre-high fence, consisting of 12 strands of alternating live electrical and grounded wires. The perimeter fence at our study site was patrolled daily and meticulously maintained by teams of rangers and workmen. The primary purpose of the fence was to segregate the wildlife from the neighbouring communities, thereby reducing human-wildlife conflict. The fence also acted as a secondary antipoaching deterrent, but the main anti-poaching efforts were through armed patrols, aerial surveillance and community intelligence. The perimeter fence was continuous except for a few manned gates permitting vehicle traffic and for the fencegaps designed for wildlife traffic (see Fig.1).

\section{Fence-gaps}

The northern fence-gap was put in place in 1994, at the same time as the perimeter fence was completed, and leads into the Leparua agro-pastoral community that has a population of approximately 3500 people over an area of 34000 ha with over 25000 head of cattle, camel (Camelus dromedarius), sheep (Ovis aries), and goats (Capra aegagrus hircus). Six ethnic, semi-nomadic tribes share the land, and conflict over grazing pastures is common. The western fence-gap (opened in 2009) connects Lewa to the neighbouring Borana 


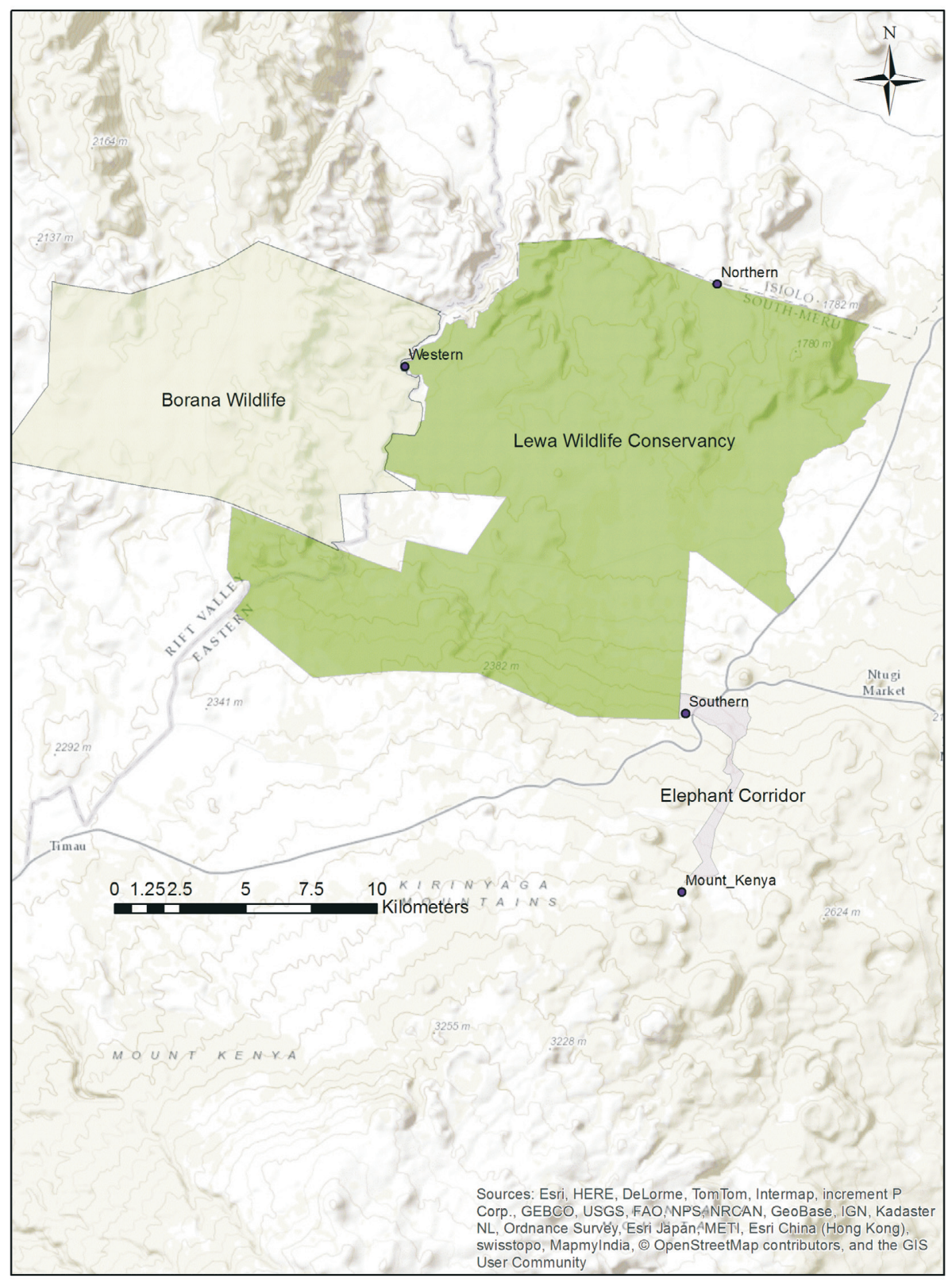

Fig. 1. Map of study site (dark green) with elephant corridor and fence-gaps (Northern, Southern and Western).

conservancy. The exact location of the western gap was chosen at the site of heavy historical elephant damage. The Borana wildlife conservancy is a 13000 ha property that has a diverse suite of wildlife and is also a functioning cattle ranch. In late 2011, Lewa opened a southern fence-gap that leads into a $14 \mathrm{~km}$ elephant corridor (Nyaligu \& Weeks, 2013) which links Lewa to the Mount Kenya National Forest Reserve. There is also a fourth fence-gap, excluded from this study, at the Mount Kenya end of the corridor as this fence-gap is a secondary exit, distal from the conservancy by $14 \mathrm{~km}$.

\section{Fence-gap design}

The fence-gap design at the study site consisted of a sloping, loose rock wall built to a height of approximately one and a half metres in height and 


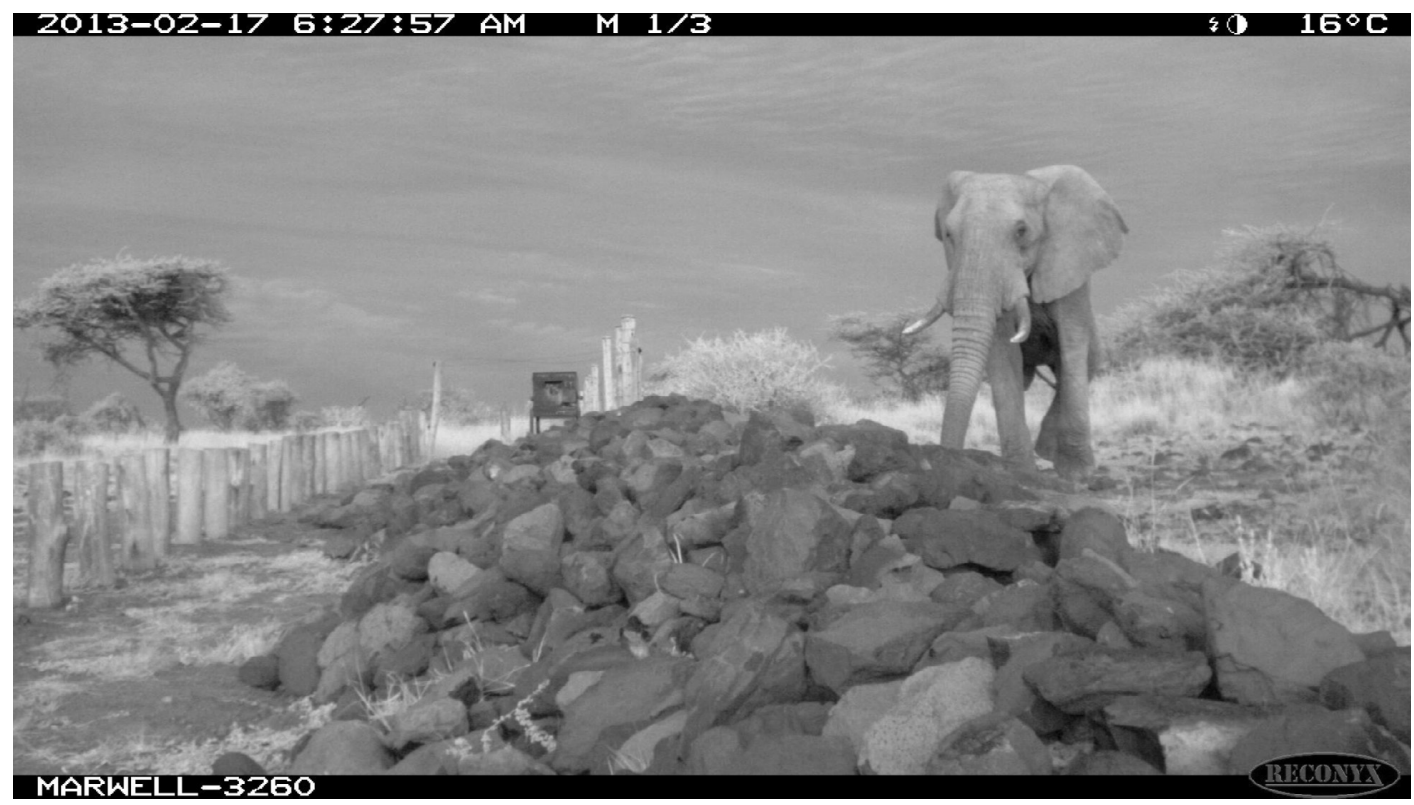

Fig. 2. An elephant returning through the northern fence-gap. Note new bollards to restrict rhino movement. Lewa, February 2013.

spanning the whole length of the fence-gaps $(20-30 \mathrm{~m})$. The rock wall, fence-gap design exploited the rhino's perceived poor ability to climb loose rocks. However, in 2012, after two rhinos managed to climb out of Lewa, management modified the fence-gap design by adding low bollards in an attempt to make it more difficult for rhino to squeeze through (see Fig. 2). This specialized fence-gap design, because of its elevated wall-like feature, is not necessarily easily discoverable or scalable and we thus wanted to test its suitability for other species by recoding usage patterns.

\section{Suitability of fence-gap design}

We tested if this specialized fence-gap design was suitable (discoverable and accessible) to permit the movement of all species except for rhino by monitoring the movement of wildlife at each gap. We monitored the three fence-gaps using infrared motion-triggered cameras (Reconyx RC60HO Hyperfire, Holmen, WI) from 2010 to 2013. We started monitoring the northern fencegap with camera-traps in January 2010 and the western fence-gap in March 2011 and then the southern fence-gap in February 2012. We positioned the cameras to maximize the field of view in each particular camera trap set-up. We mounted cameras in 'elephant-proof', custom built steel housings. There was one camera at the western fence-gap, one camera at the southern gap inside a narrow highway underpass approximately $500 \mathrm{~m}$ south of the southern fence-gap, and two cameras facing each other at the wider northern fence-gap. At the northern fence-gap, data from the second camera were used mainly as a back-up, if the other camera failed, for difficult species identification or for counting large groups of animals. We configured all of the cameras for a three-exposure burst upon trigger by their built-in motion detectors and set for rapid-fire to ensure continuous shooting for as long as their sensors detected motion. Camera-traps recorded many images per crossing events. Images were stored on 32GB Secure Digital (SD) memory cards. Conservancy research staff collected data roughly every two weeks from the cameras, uploaded the photographs into a central database and recorded the date, time, species, number of individuals crossing, and direction of travel into a spreadsheet. Traffic volume for each species was calculated by counting all of the individuals crossing in both directions at each respective fence-gap. One of the challenges of monitoring the effectiveness of fence-gap usage is discriminating between individuals using the gaps. We could recognize certain individuals of well-marked species (zebra, Equus quagga and Equus grevyi, and giraffe, 


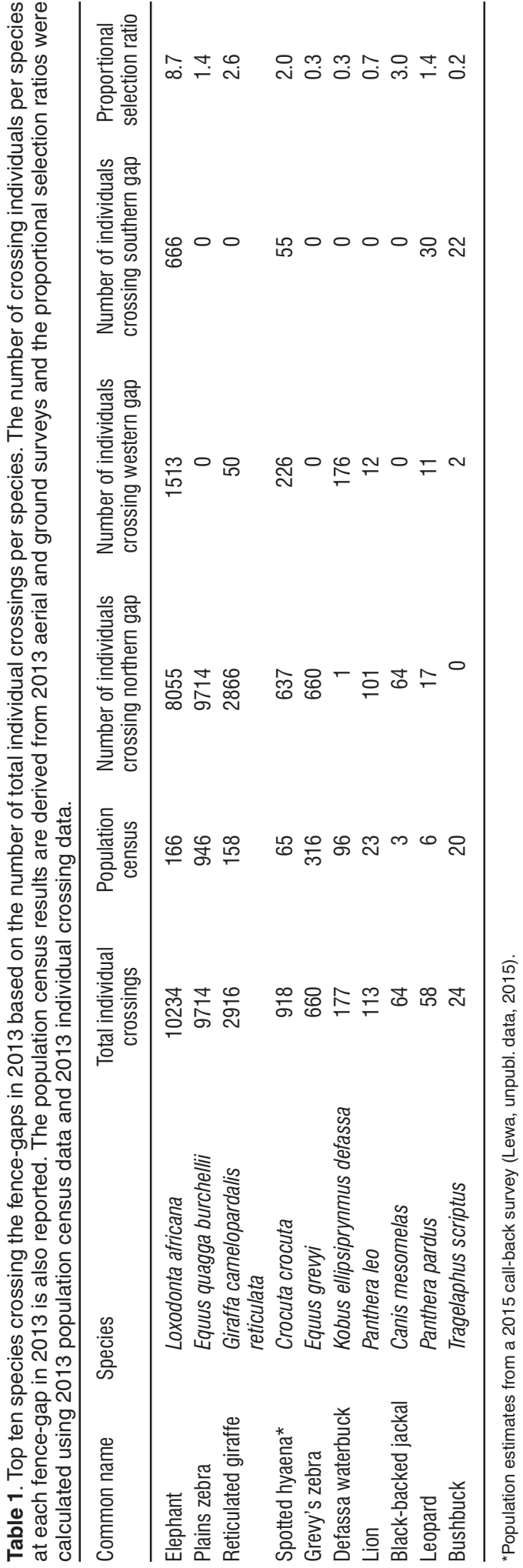

Giraffa camelopardalis reticulata) by their unique patterns. For example, we could identify one particular male Grevy's zebra, as a wound had left an unusual stripe pattern on one of its flanks. This territorial individual was a repeat user of the northern fence-gap. In 2010, we were able to identify this male crossing the fence-gap in excess of 80 times (out of 396 total number of individuals Grevy's captured in 2010), either alone, or with one or two females. We could also detect the regular use of the fence-gap by certain reticulated giraffes and certain collared elephants but not with the same regularity. Consequently, the reported totals of individual animals crossings per species are an overestimation of the true number of unique individuals using the fence-gaps. While we recognize this limitation, the purpose of this study was to examine the ease, the frequency of use, and the diversity of species accessing areas outside the conservancy, and in this capacity, the regular use of the fence-gaps by some individuals is viewed as an indication of their ease of use and accessibility.

\section{Proportional selection ratio}

In an effort to better understand the accessibility and attractiveness of the fence-gap locations, we calculated a proportional selection ratio. For this ratio we used the total number of crossing individuals per species as the numerator, divided by the total number of crossing individuals by all species; and for the denominator we used the total population of that species divided by the total population number of all species. We used population numbers based on the annual population census numbers collected by Lewa staff using standardized aerial and ground surveys in 2013. A usage ratio greater than one indicates that a species has used the fencegaps to a greater extent than could be expected given its population and could be seen as 'preferring' the fence-gaps (i.e. more likely to use than a species with a lower ratio). We would expect that certain species, based on their life histories, would be more frequent users of migration corridors, and that a lack of movement through the gaps by these species might indicate that there were some issues with gap location or design. We reported the proportional selection ratio for the top-ten species using the fence-gaps (we selected the top-ten species based on the total numbers of individuals crossing the fence-gaps in 2013). Although we did not have 2013 census data for the spotted hyaena (Crocuta crocuta), we used population estimates derived from a 2015 call up survey 
(Groom, Funston \& Mandisodza, 2014) that estimated the population size at 65 to 80 individuals (Lewa, unpubl. data, 2015).

\section{RESULTS}

\section{Suitability of fence-gap design}

We captured camera data for a combined 2041 trap-days over the 2010-2013 period at the three fence-gaps (Northern: 1128 days, Western: 550 days, Southern: 363 days). During 2010-2013, we recorded 50444 crossing animals of 39 species (37 species of mammals and two species of birds) through the Lewa fence-gaps (45 826 at the northern fence-gap, 1176 at the southern fence-gap, 3442 at the western fence-gap). Because we had camera-traps at all gaps in 2013, only the species usage per fence-gap for the top-ten species in 2013 is shown in Table 1.

Elephants, plains zebra and giraffe accounted for the majority of the animal traffic through the fence-gaps. The major predators, spotted hyaena, lion (Panthera leo), and leopard (Panthera pardus), were also frequent users of the fencegaps. Rhinos were not photographed trying to cross the fence-gaps after the implementation of the modification to the fence design in 2012. We have reported the aggregated fence-gap crossings for all 39 species captured by the camera-traps over 2010-2013 period, as well as the species with a population census count but without a crossing record in Appendix 1.

\section{Proportional selection ratio}

The results of the proportional selection ratio analysis are shown in Table 1 for the top-ten species in 2013 and in Appendix 1 for all species for 2010-2013. Elephant, plains zebra, giraffe, spotted hyaena, leopard and black-backed jackal (Canis mesomelas) showed a high propensity to use the gaps in relation to other species in the conservancy.

\section{DISCUSSION}

\section{Suitability of fence-gap design and fence-gap usage patterns}

The fence-gaps were effective at blocking the passage of rhino, especially once the gaps were modified with additional bollards. The fence-gaps were also effective at allowing elephants and many other species to move in or out of the study site given that a wide variety of species located and used one or more of the fence-gaps. Based on these data, we feel confident in asserting that this specialized fence-gap design is both discoverable and usable by most migratory species. We found that a different mix of species was present at each fence-gap but that only elephants, spotted hyaenas and leopards used all fence-gaps extensively.

\section{Proportional selection ratio}

The proportional selection ratio highlights which species were more likely to migrate or exploit areas outside the boundaries of the conservancy, relative to other species. A high usage ratio could indicate that the foraging or breeding needs of a particular species are not met inside the conservancy.

Conversely, Grant's gazelle (Nanger granti), Beisa's oryx (Oryx gazella beisa), buffalo (Syncerus caffer) and impala (Aepyceros melampus) stand out for having large in situ populations and proportional selection ratios near zero (see Appendix 1). These species are capable of long-range migrations (Du Toit, 1990; Estes, 1967; Murray, 2008; Naidoo, Du Preez, Stuart-Hill, Beytell \& Taylor, 2014; Smithers, 1983; Walther, 1972), but generally have smaller home ranges than the species represented with high ratios. Would these low selection ratio species use fence-gaps more frequently if these were located in areas more proximate to their main home ranges? Was there something in the location or the design of the fence-gaps that made them difficult to access? As structures designed to facilitate movement of wildlife across fenced boundaries, the fence-gaps do appear to have been discovered by many species and seemed to function effectively. They appeared to pose no obvious mechanical difficulties for most individuals to cross, although we did record an elephant tripping during a rainy crossing and several juvenile giraffes hesitating and turning back from the fence-gaps. The fence-gap design does not appear to impede movement, but the different levels of usage relative to population density might suggest that more fence-gaps in different locations might be useful, depending upon species-specific movement requirements and life history characteristics, among other factors.

For territorial predators, the usage of the fencegaps could indicate a level of normal exploratory activity (Van der Waal, Mosser \& Packer, 2009) or it could be an indication that these species have reached their local carrying capacity (Hayward, O'Brien \& Kerley, 2007; Honer, Wachter, East, 
Runyoro \& Hofer, 2005). Intra- and/or interspecies competition, lack of prey and territoriality battles may be encouraging exploratory movements out of the conservancy by individuals relegated to sub-optimal foraging areas (Honer et al., 2005). The regular access into a pastoral community through the northern fence-gap by all predators, and most frequently by the spotted hyaena, also supports evidence that predators, and particularly hyaenas, readily use human-dominated landscape (Kissui, 2008; Kolowski \& Holekamp, 2008; Yirga et al., 2013). Whatever the motivating factor for the predator movement through the fence-gaps, it appears that the gap design and locations permitted dispersal and/or exploratory foraging on the landscape.

\section{Risks to the community}

The success of the fence-gaps at permitting movement off the conservancy is not without its risks to the surrounding communities or to the wildlife population (Hazzah et al., 2014). Lewa has developed an active predator early-warning system that alerts neighbouring communities when predator tracks are detected at the northern fencegap and has previously implemented a compensation programme for neighbouring pastoralists that suffer from depredation of their livestock and for agriculturalists that suffer from elephant cropraiding.

\section{Risks of the development of a prey-trap}

The compromise between an open landscape and one with only a few fence-gaps is that all of the mammal traffic that moves on or off the conservancy needs to do so at a few specific locations. This spatial predictability of animal movement could potentially lead to predators exploiting the fence-gaps and eventually lead to an imbalance of the predator-prey dynamic. A recent study by Dupuis-Desormeaux et al. (2015) found that fence gaps on the Lewa and neighbouring Borana conservancies did not act as prey-traps, but managers contemplating the use of fence-gaps should monitor the dynamics of predator-prey interactions near the fence gaps for the potential emergence of prey-traps.

\section{CONCLUSIONS}

Fencing will continue to be the first line of defense against human-wildlife conflicts and poaching. Any amelioration of the isolating effects of completely fencing a wildlife habitat should be considered. Our data show that the design of the fence-gaps permits landscape connectivity, as intended, for the main migratory species present on the conservancy as well as effectively preventing the escape of an endangered rhino species. We conclude that the fence-gap design is well suited to rhino conservancies that need to manage elephant movement and want to encourage more natural animal movement and landscape connectivity.

\section{REFERENCES}

Albertson, A. (1998). Northern Botswana veterinary fences: critical ecological impacts. Maun, Botswana: Okavango Peoples Wildlife Trust.

Aresco, M. J. (2005). Mitigation measures to reduce highway mortality of turtles and other herpetofauna at a north Florida lake. Journal of Wildlife Management, 69(2), 549-560.

Atwood, T. C., Young, J. K., Beckmann, J. P., Breck, S.W., Fike, J., Rhodes Jr, O. E. \& Bristow, K. D. (2011). Modeling connectivity of black bears in a desert sky island archipelago. Biological Conservation, 144(12), 2851-2862.

Beier, P. \& Noss, R. F. (1998). Do habitat corridors provide connectivity? Conservation Biology, 12(6), 1241-1252.

Bouché, P., Douglas-Hamilton, I., Wittemyer, G., Nianogo, A.J., Doucet, J-L., Lejeune, P. \& Vermeulen, C.. (2011). Will elephants soon disappear from West African savannahs? PLOS ONE, 6(6). DOI: 10.1371/journal.pone.0020619

Brenneman, R. A., Bagine, R. K., Brown, D. M., Ndetei, R. \& Louis Jr, E.E. (2009). Implications of closed ecosystem conservation management: the decline of Rothschild's giraffe (Giraffa camelopardalis rothschildi) in Lake Nakuru National Park, Kenya. African Journal of Ecology, 47(4), 711-719.

Clevenger, A.P., Chruszcz, B. \& Gunson, K.E. (2001). Highway mitigation fencing reduces wildlife-vehicle collisions. Wildlife Society Bulletin, 29(2), 646-653.

Davies, T.E., Wilson, S., Hazarika, N., Chakrabarty, J., Das, D., Hodgson, D.J. \& Zimmermann, A. (2011). Effectiveness of intervention methods against cropraiding elephants. Conservation Letters, 4(5), 346-354. DOI: 10.1111/j.1755-263X.2011.00182.x

Debinski, D.M. \& Holt, R.D. (2000). A survey and overview of habitat fragmentation experiments. Conservation Biology, 14(2), 342-355.

Di Minin, E., Hunter, L.T.B., Balme, G.A., Smith, R.J., Goodman, P.S. \& Slotow, R. (2013). Creating larger and better connected protected areas enhances the persistence of big game species in the MaputalandPondoland-Albany biodiversity hotspot. PLOS ONE, 8(8), e71788. DOI: 10.1371/journal.pone.0071788

Douglas-Hamilton, I., Krink, T. \& Vollrath, F. (2005). Movements and corridors of African elephants in relation to protected areas. Naturwissenschaften, 92(4), 158-163.

Du Toit, J.T. (1990). Home range-body mass relations: a field study on African browsing ruminants. Oecologia, 85(2), 301-303.

Dupuis-Desormeaux, M., Davidson, Z., Mwololo, M., 
Kisio, E., Taylor, S. \& MacDonald, S.E. (2015). Testing the prey-trap hypothesis at two wildlife conservancies in Kenya. PLOS ONE, 10(10), e013957.

Estes, R.D. (1967). The comparative behavior of Grant's and Thompson's gazelles. Journal of Mammalogy, 48(2), 189-209.

Fahrig, L. (2007). Non-optimal animal movement in human-altered landscapes. Functional Ecology, 21(6), 1003-1015.

Galanti, V., Preatoni, D., Martinoli, A., Wauters, L.A. \& Tosi, G. (2006). Space and habitat use of the African elephant in the Tarangire-Manyara ecosystem, Tanzania: implications for conservation. Mammalian Biology, 71(2), 99-114.

Groom, R.J., Funston, P.J. \& Mandisodza, R. (2014). Surveys of lions Panthera leo in protected areas in Zimbabwe yield disturbing results: what is driving the population collapse? Oryx, 48(3), 385-393. DOI: $10.1017 / \mathrm{s} 0030605312001457$

Guerbois, C., Chapanda, E. \& Fritz, H. (2012). Combining multi-scale socio-ecological approaches to understand the susceptibility of subsistence farmers to elephant crop raiding on the edge of a protected area. Journal of Applied Ecology, 49(5), 1149-1158. DOI: 10.1111/j.1365-2664.2012.02192.x

Harrington, J.L. \& Conover, M.R. (2006). Characteristics of ungulate behavior and mortality associated with wire fences. Wildlife Society Bulletin, 34(5), 1295-1305. DOI: 10.2193/0091-7648(2006)34[1295:coubam]2.0.co;2

Hayward, M.W. \& Kerley, G.I.H. (2009). Fencing for conservation: restriction of evolutionary potential or a riposte to threatening processes? Biological Conservation, $142(1), 1-13$.

Hayward, M.W., O’Brien, J. \& Kerley, G.I.H. (2007). Carrying capacity of large African predators: predictions and tests. Biological Conservation, 139(1-2), 219-229. DOI: 10.1016/j.biocon.2007.06.018

Hazzah, L., Dolrenry, S., Naughton, L., Edwards, C.T.T., Mwebi, O., Kearney, F. \& Frank, L. (2014). Efficacy of two lion conservation programs in Maasailand, Kenya. Conservation Biology, 28(3), 851-860. DOI: 10.1111/cobi.12244

Hoare, R.E. (1992). Present and future use of fencing in the management of larger African mammals. Environmental Conservation, 19(2), 160-164.

Hoare, R. (2012). Lessons from 15 years of human-elephant conflict mitigation: management considerations involving biological, physical and governance issues in Africa. Pachyderm, 51, 60-74.

Honer, O.P., Wachter, B., East, M.L., Runyoro, V.A. \& Hofer, H. (2005). The effect of prey abundance and foraging tactics on the population dynamics of a social, territorial carnivore, the spotted hyena. Oikos, 108(3), 544-554. DOI: 10.1111/j.0030-1299.2005.13533. $\mathrm{x}$

Hunter, L.T.B. (2007). Restoring lions Panthera leo to northern KwaZulu-Natal, South Africa: short-term biological and technical success but equivocal long-term conservation. Oryx, 41(2), 196-204.

Kikoti, A.P., Griffin, C.R. \& Pamphii, L. (2010). Elephant use and conflict leads to Tanzania's first wildlife conservation corridor. Pachyderm, 48(1), 57-66.
Kioko, J., Muruthi, P., Omondi, P. \& Chiyo, P. I. (2008). The performance of electric fences as elephant barriers in Amboseli, Kenya. South African Journal of Wildlife Research, 38(1), 52-58.

Kissui, B.M. (2008). Livestock predation by lions, leopards, spotted hyenas, and their vulnerability to retaliatory killing in the Maasai steppe, Tanzania. Animal Conservation, 11(5), 422-432. DOI: 10.1111/j.1469-1795.2008.00199.x

Kolowski, J.M. \& Holekamp, K.E. (2008). Effects of an open refuse pit on space use patterns of spotted hyenas. African Journal of Ecology, 46(3), 341-349. DOI: 10.1111/j.1365-2028.2007.00846.x

Loarie, S.R., Aarde, R.J.V. \& Pimm, S.L. (2009). Fences and artificial water affect African savannah elephant movement patterns. Biological Conservation, 142(12), 3086-3098.

Massey, A.L., King, A.A. \& Foufopoulos, J. (2014). Fencing protected areas: a long-term assessment of the effects of reserve establishment and fencing on African mammalian diversity. Biological Conservation, 176, 162-171. DOI: 10.1016/j.biocon.2014.05.023

Mbaiwa, J.E. \& Mbaiwa, O.I. (2006). The effect of veterinary fences on wildlife populations in Okavango Delta, Botswana. International Journal of Wilderness, 12, 17-41.

McCollister, M.F. \& Van Manen, F.T. (2010). Effectiveness of wildlife underpasses and fencing to reduce wildlife-vehicle collisions. Journal of Wildlife Management, 74(8), 1722-1731.

Messer, K.D. (2010). Protecting endangered species: when are shoot-on-sight policies the only viable option to stop poaching? Ecological Economics, 69(12), 2334-2340.

Murray, M.G. (2008). Home range, dispersal and the clan system of impala. African Journal of Ecology, 20(4).

Naidoo, R., Du Preez, P., Stuart-Hill, G., Beytell, P. \& Taylor, R. (2014). Long-range migrations and dispersals of African buffalo (Syncerus caffer) in the Kavango-Zambezi Transfrontier Conservation Area. African Journal of Ecology, 52(4), 581-584.

Newmark, W.D. (2008). Isolation of African protected areas. Frontiers in Ecology and the Environment, 6(6), 321-328.

Nyaligu, M.O. \& Weeks, S. (2013). An elephant corridor in a fragmented conservation landscape: preventing the isolation of Mount Kenya National Park and National Reserve. Parks, 19(1), 91-101.

Olsson, M.P.O. \& Widen, P. (2008). Effects of highway fencing and wildlife crossings on moose Alces alces movements and space use in southwestern Sweden. Wildlife Biology, 14(1), 111-117.

Packer, C., Loveridge, A., Canney, S., Caro, T., Garnett, S.T., Pfeifer, M., ... Polasky, S. (2013). Conserving large carnivores: dollars and fence. Ecology Letters, 16(5), 635-641. DOI: 10.1111/ele.12091

Smithers, R.H.N. (1983). The mammals of the southern African sub-region. Pretoria: Struik.

Taylor, R.D. \& Martin, R.B. (1987). Effects of veterinary fences on wildlife conservation in Zimbabwe. Environmental Management, 11(3), 327-334.

Tischendorf, L. \& Fahrig, L. (2000). On the usage and measurement of landscape connectivity. Oikos, 90(1), 7-19. 
Thomas, B., Holland, J.D. \& Minot, E.O. (2008). Elephant (Loxodonta africana) home ranges in Sabi Sand Reserve and Kruger National Park: a five-year satellite tracking study. PLOS ONE, 3(12).

Thouless, C. R. \& Sakwa, J. (1995). Shocking elephants: fences and crop raiders in Laikipia District, Kenya. Biological Conservation, 72(1), 99-107.

Vanak, A.T., Thaker, M. \& Slotow, R. (2010). Do fences create an edge-effect on the movement patterns of a highly mobile mega-herbivore? Biological Conservation, 143(11), 2631-2637.

VanderWaal, K.L., Mosser, A. \& Packer, C. (2009). Optimal group size, dispersal decisions and postdispersal relationships in female African lions. Animal Behaviour, 77(4), 949-954. DOI: 10.1016/j.anbehav.2008.12.028

Walpole, M.J. \& Leader-Williams, N. (2002). Tourism and flagship species in conservation. Biodiversity and Conservation, 11(3), 543-547.

Walther, F.R. (1972). Social grouping in Grant's gazelle (Gazella granti Brooke, 1872) in Serengeti National Park. Z. Tierpsycol (Journal of Animal Breeding and Genetics), 31, 348-403.

White, F. (1983). Vegetation of Africa - a descriptive memoir to accompany the Unesco/AETFAT/UNSO vegetation map of Africa Natural Resources Research Report XX (p. 356). Paris, France: U.N. Educational, Scientific and Cultural Organization.

Yirga, G., Ersino, W., De Iongh, H.H., Leirs, H., Gebrehiwot, K., Deckers, J. \& Bauer, H. (2013). Spotted hyena (Crocuta crocuta) coexisting at high density with people in Wukro district, northern Ethiopia. Mammalian Biology, 78(3), 193-197. DOI: 10.1016/j.mambio.2012.09.001

Responsible Editor: N. Owen-Smith 
Dupuis-Désormeaux et al: Fence-gaps in a black rhinoceros conservancy in Kenya

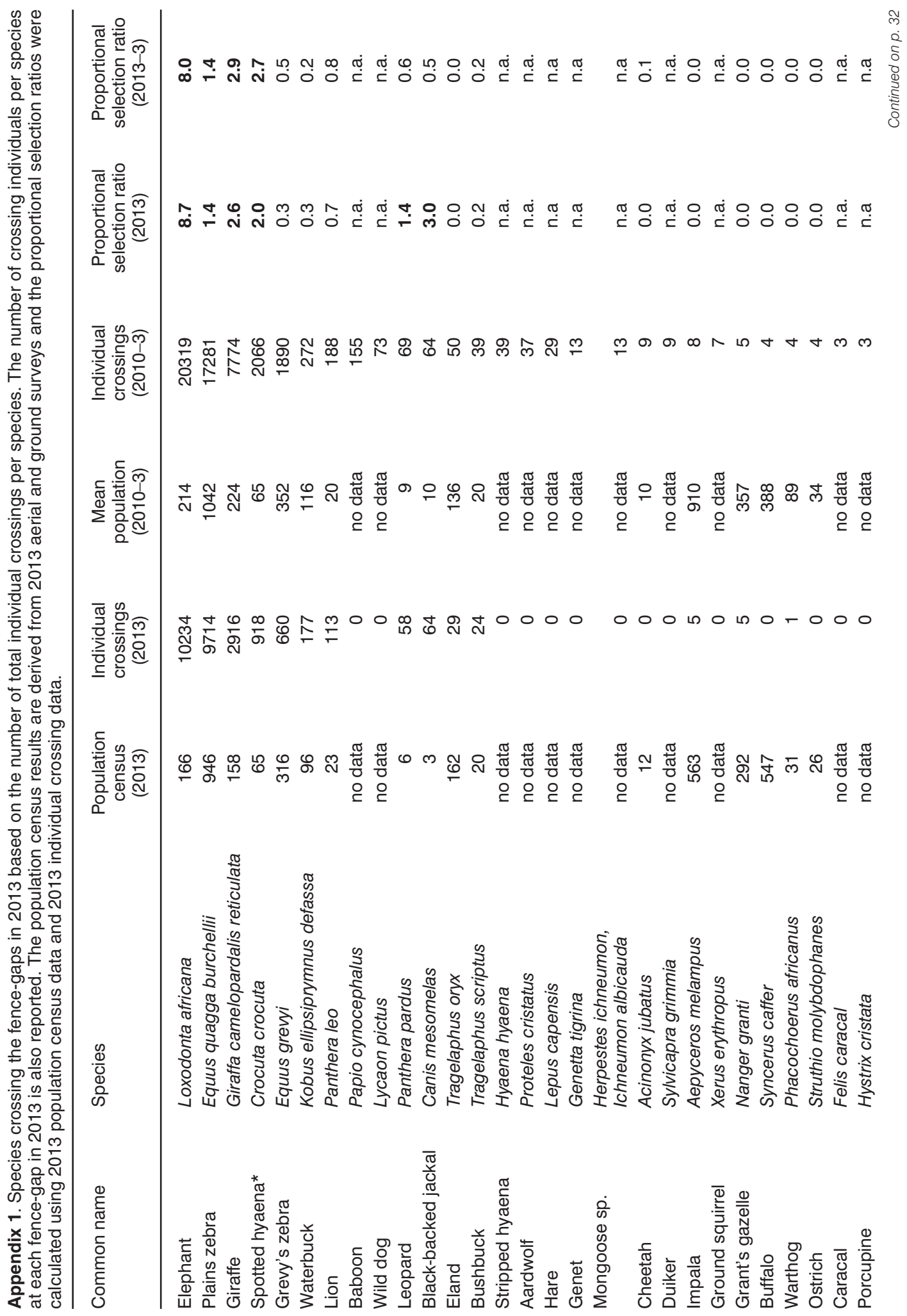




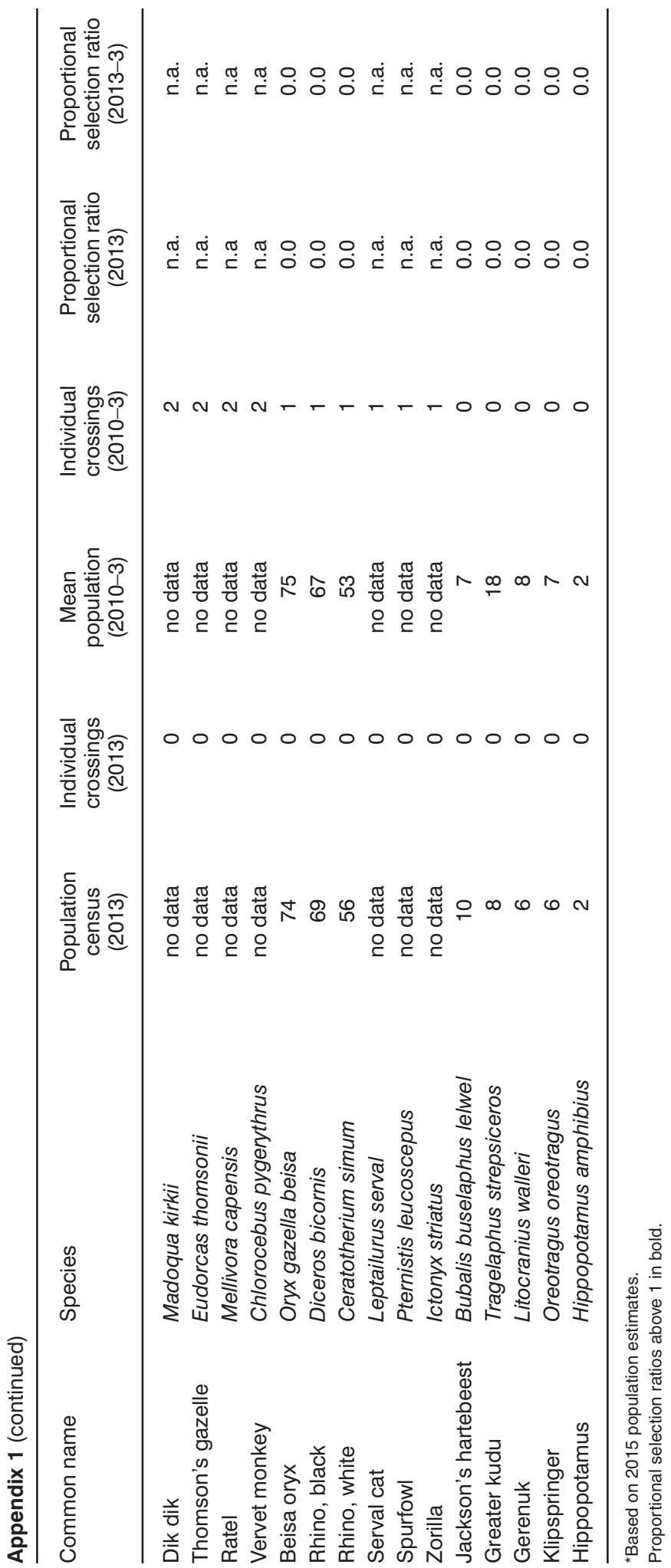

